\title{
Significance of Lateral Pelvic Lymph Node Size in Predicting Metastasis and Prognosis in Rectal Cancer
}

\author{
DONGHA LEE ${ }^{1}$, TAKERU MATSUDA ${ }^{2,3}$, KIMIHIRO YAMASHITA ${ }^{3}$, HIROSHI HASEGAWA ${ }^{3}$, \\ MASASHI YAMAMOTO ${ }^{3}$, SHINGO KANAJI $^{3}$, TARO OSHIKIRI ${ }^{3}$, TETSU NAKAMURA $^{3}$, \\ SATOSHI SUZUKI ${ }^{3}$, TAKUMI FUKUMOTO ${ }^{1}$ and YOSHIHIRO KAKEJI ${ }^{3}$ \\ ${ }^{1}$ Division of Hepato-Biliary-Pancreatic Surgery, Department of Surgery, \\ Kobe University Graduate School of Medicine, Kobe, Japan; \\ ${ }^{2}$ Division of Minimally Invasive Surgery, Department of Surgery, \\ Kobe University Graduate School of Medicine, Kobe, Japan; \\ ${ }^{3}$ Division of Gastrointestinal Surgery, Department of Surgery, \\ Kobe University Graduate School of Medicine, Kobe, Japan
}

\begin{abstract}
Aim: To evaluate the clinical significance of lateral pelvic lymph node (LLN) size in predicting pathological metastasis and prognosis in rectal cancer treated with preoperative chemoradiotherapy (CRT) followed by surgery. Patients and Methods: Fifty-two patients with rectal cancer who underwent curative surgery after preoperative CRT were included. Fifteen patients underwent total mesorectal excision (TME) alone, while 37 patients underwent TME with $L L N$ dissection for clinical $L L N$ metastasis. Results: Pathological metastasis was identified in seven (2.6\%) out of 270 resected LLNs in six (16.2\%) out of 37 patients. The cut-off value of the short-axis diameter was $7.0 \mathrm{~mm}$ before and $6.0 \mathrm{~mm}$ after CRT. The 5-year recurrencefree survival rate was significantly higher in patients with LLNs $<7.0 \mathrm{~mm}$ than in those with LLNs $\geq 7.0 \mathrm{~mm}(85.7 \%$ versus $56.8 \%, p=0.038)$. Conclusion: Short-axis diameter of LLNs of $7.0 \mathrm{~mm}$ seems to be an optimal cut-off value before CRT for predicting pathological metastasis and prognosis.
\end{abstract}

Total mesorectal excision (TME) following preoperative chemoradiotherapy (CRT) is the standard treatment for patients with locally advanced low rectal cancer in western countries because it achieves a local recurrence rate of less than $10 \%(1-3)$. However, the effect of this multimodal

Correspondence to: Takeru Matsuda, MD, Ph.D., Division of Gastrointestinal Surgery, Department of Surgery, Kobe University Graduate School of Medicine, 7-5-2 Kusunoki-chou, Chuo-ku, Kobe 650-0017, Japan. Tel: +81 783825925, Fax: +81 783825939, e-mail: takerumatsuda@nifty.com

Key Words: Rectal cancer, lateral pelvic lymph node, preoperative chemoradiotherapy. therapy on patients with rectal cancer with pathological lateral pelvic lymph node (LLN) metastasis is unknown because such data are unavailable. In Japan, TME with LLN dissection (LLND) is generally performed in these patients to improve local control and overall survival (OS). In fact, the Japanese Society for Cancer of the Colon and Rectum Guidelines recommend bilateral LLND for patients with locally advanced low rectal cancer that extends below the peritoneal reflection (4). In previous studies in Japan, pathologically positive LLN metastasis was found in approximately $15 \%$ of patients with rectal cancer who underwent LLND (5-8). The oncological outcomes after TME with bilateral LLND are unfortunately poor in patients with rectal cancer with LLN metastasis (9-11).

Considering these outcomes, TME combined with LLND following preoperative CRT seems to be a valid and effective approach, at least for those patients with rectal cancer with clinically positive LLNs. We performed selective LLND after preoperative CRT for such patients and reported on good oncological outcomes of this treatment strategy (12). In our treatment strategy, LLND was performed only in patients with clinically positive LLNs on the basis of pretreatment images. Patients with clinically negative LLNs underwent only TME after preoperative CRT. Our criteria for performing LLND include the presence of LLNs with a short-axis diameter of $\geq 8 \mathrm{~mm}$ on computed tomography (CT) or magnetic resonance imaging (MRI) or LLNs showing a high-intensity spot on pretreatment positron-emission tomography (PET) images. However, various size criteria to predict LLN metastasis on preoperative CT or MRI have been previously reported, and whether our criteria are valid remains to be proven.

In the present study, we therefore, intended to investigate the relationship between the size of resected LLN specimens and their pathologically confirmed metastatic status. The 
purpose of this study was to evaluate the validity and clinical significance of our size criteria and determine the optimal cut-off value of LLN size by receiver operating characteristic (ROC) curve analysis.

\section{Patients and Methods}

Study population. A total of 52 patients with locally advanced rectal cancer who underwent curative surgery after preoperative CRT between November 2005 and September 2017 were included in this study. Of the 52 patients included in the study, 15 underwent TME alone (TME group) because of clinically negative LLNs, while the remaining 37 underwent TME with LLND (TME with LLND group) due to clinically positive LLN metastasis. Their data were retrospectively analyzed. The median follow-up duration was 45.0 (range $=6.0-151.0)$ months. Tumors were classified according to the seventh edition of the American Joint Committee on Cancer classification guidelines (13). Postoperative complications were assessed according to the Extended Clavien-Dindo classification of surgical complications (14).

This retrospective study was conducted with approval of the Institutional Review Board and Ethics Committee of the Graduate School of Medicine, Kobe University School of Medicine (approval number: 180267).

Treatment strategy. Our treatment strategy for locally advanced low rectal cancer was described previously (12). Briefly, preoperative CRT consisted of a total radiation dose of 45 Gy and oral 5fluorouracil-based chemotherapy. Radiotherapy was delivered in 25 fractions over 5 weeks, and the lateral pelvic area was included in the radiation target volume. Chemotherapy was started on the first day of radiotherapy. Tegafur-uracil $\left(200 \mathrm{mg} / \mathrm{m}^{2} /\right.$ day $)$ and leucovorin ( $75 \mathrm{mg} /$ day) were orally administered for 28 days. The imaging studies were repeated 4-6 weeks after the completion of CRT. Patients in whom metastasis of the para-aortic lymph nodes or distant organs was suspected after CRT were excluded from the indications for curative surgery. Surgery was performed 6-8 weeks after the completion of CRT. TME was performed through an open or laparoscopic approach. LLND was performed only in patients with clinically positive LLNs on the basis of pretreatment images. LLNs with a short-axis diameter of $\geq 8 \mathrm{~mm}$ on CT or MRI or showing a high-intensity spot on PET images, regardless of any shrinkage of the lymph nodes after CRT, and LLNs that had increased in size on CT or MRI images after CRT were considered as clinically positive for metastasis. LLND was performed only on the side of clinically positive LLNs, with the internal iliac and obturator regions dissected as the standard LLND procedure. When LLN metastasis was suspected on both sides, bilateral LLND was performed. Inguinal lymph node dissection was performed following the same principle.

Determination of the cut-off value of LLN size. The short-axis diameter of each LLN was measured via CT or MRI images before and after CRT. All resected LLN specimens were histologically examined for their pathological status. The cut-off value of LLN size to predict pathological metastasis before and after CRT was determined by the ROC curve analysis.

Follow-up. Tumor markers carcinoembryonic antigen (CEA) and carbohydrate antigen 19-9 were examined every 3 months in the first 3 years and every 6 months thereafter. CT and abdominal ultrasonography were performed every 6 months. Total colonoscopy was conducted every 12 months. Local recurrence was defined as recurrence within the pelvic cavity, and distant recurrence was defined as any recurrence outside the pelvic cavity.

Statistical analysis. Statistical analyses were performed using JMP ${ }^{\circledR}$ software 11 (SAS Institute Inc., Cary, NC, USA). Continuous variables were expressed as the median (range). Analysis of survival time from surgery was performed using the Kaplan-Meier method, and univariate survival comparison was performed using the logrank test. Variables with a $p$-value of less than 0.15 in univariate analysis were further evaluated in multivariate analysis using the Cox proportional hazards model. A $p$-value of less than 0.05 was considered statistically significant.

\section{Results}

The patient and tumor characteristics in this study are shown in Table I. There were no significant differences in the age, sex, clinical stage, postneoadjuvant pathological (yp) TNM stage, pretreatment CEA level, histological type, and the rate of adjuvant chemotherapy between the groups. Pathologically positive LLNs were identified in six (16.2\%) out of the 37 patients who underwent LLND in the TME with LLND group.

The surgical and oncological outcomes are shown in Table II. The operative time was significantly longer and the estimated blood loss tended to be larger when LLND was performed ( $p=0.015$ and $p=0.053$, respectively). There was no significant difference in the rate of postoperative complications between the two groups $(p=0.743)$. Local recurrence developed in nine patients in the TME with LLND group, but in none in the TME group $(17.3 \%$ versus $0 \% ; p=0.066)$. Distant metastasis developed in 10 patients $(27.0 \%)$ in the TME with LLND group and two (13.3\%) in the TME group ( $p=0.479)$.

Of the 270 LLNs resected in 37 patients, only seven $(2.6 \%)$ showed pathological metastasis. The median short-axis diameter before CRT was $4.7 \mathrm{~mm}$ (range=2.0-15.6 $\mathrm{mm}$ ) for LLNs without pathological metastasis and $11.5 \mathrm{~mm}$ (range $=5.2-30.1 \mathrm{~mm}$ ) for LLNs with pathological metastasis $(p<0.001)$ (Figure 1). After CRT, it was $4.0 \mathrm{~mm}$ (range=1.79.8) for LLNs without pathological metastasis and $11.5 \mathrm{~mm}$ (range $=5.8-20.7 \mathrm{~mm}$ ) for LLNs with pathological metastasis $(p<0.001)$. The short-axis diameter of LLNs with pathological metastasis was significantly larger than that of LLNs without pathological metastasis, both before and after CRT.

The ROC curves for the per-patient prediction of nodal status before and after CRT are shown in Figure 2. The area under the curve (AUC) before and after CRT was 0.92 and 0.97 , respectively. Based on the ROC curve analysis, the cutoff value of the short-axis diameter of LLNs before and after CRT was $7.0 \mathrm{~mm}$ and $6.0 \mathrm{~mm}$, respectively. The sensitivity, specificity, positive predictive value, and negative predictive value were $85.7 \%, 84.0 \%, 12.5 \%$, and $99.5 \%$ before CRT and $100 \%, 87.8 \%, 17.9 \%$, and $100 \%$ after CRT, respectively. 
Table I. Patient and tumor characteristics.

\begin{tabular}{|c|c|c|c|}
\hline & $\begin{array}{l}\text { TME } \\
(\mathrm{n}=15)\end{array}$ & $\begin{array}{l}\text { TME+LLND } \\
\quad(\mathrm{n}=37)\end{array}$ & $p$-Value \\
\hline \multicolumn{4}{|l|}{ Age, years } \\
\hline Median (range) & $66(56-77)$ & $65(39-79)$ & 0.424 \\
\hline \multicolumn{4}{|l|}{ Gender, n (\%) } \\
\hline Male & $10(66.7)$ & $25(67.6)$ & 0.950 \\
\hline Female & $5(33.3)$ & $12(32.4)$ & \\
\hline \multicolumn{4}{|l|}{ cStage*, n $(\%)$} \\
\hline II & $5(33.3)$ & $4(10.8)$ & 0.052 \\
\hline III & $10(66.7)$ & $33(89.2)$ & \\
\hline \multicolumn{4}{|l|}{ ypT*, n $(\%)$} \\
\hline pT0 & $1(6.7)$ & $6(16.2)$ & 0.134 \\
\hline $\mathrm{pTis} / \mathrm{T} 1$ & 0 & 0 & \\
\hline pT2 & $2(13.3)$ & $9(24.3)$ & \\
\hline pT3 & $12(80.0)$ & $17(46.0)$ & \\
\hline pT4 & 0 & $5(13.5)$ & \\
\hline \multicolumn{4}{|l|}{ ypN*, n (\%) } \\
\hline pNO & $7(46.6)$ & $24(64.9)$ & 0.307 \\
\hline $\mathrm{pN} 1$ & $4(26.7)$ & $9(24.3)$ & \\
\hline $\mathrm{pN} 2$ & $4(26.7)$ & $4(10.8)$ & \\
\hline \multicolumn{4}{|l|}{ ypStage*, n (\%) } \\
\hline 0 & $0(0)$ & $6(16.2)$ & 0.283 \\
\hline I & $1(6.7)$ & $5(13.5)$ & \\
\hline II & $6(40.0)$ & $13(35.1)$ & \\
\hline III & $8(53.3)$ & $13(35.1)$ & \\
\hline \multicolumn{4}{|c|}{ Pretreatment CEA, ng/ml } \\
\hline Median (range) & $4.2(1-136)$ & $5.5(1-110)$ & 0.413 \\
\hline \multicolumn{4}{|l|}{ Histological type } \\
\hline Well/moderately & $12(80.0)$ & $32(86.5)$ & 0.557 \\
\hline Poorly/other & $3(20.0)$ & $5(13.5)$ & \\
\hline \multicolumn{4}{|c|}{ Pathological LLN metastasis, $\mathrm{n}(\%)$} \\
\hline Present & NA & $6(16.2)$ & \\
\hline Absent & $15(100)$ & $31(83.8)$ & \\
\hline \multicolumn{4}{|c|}{ Adjuvant chemotherapy, n (\%) } \\
\hline Yes & $9(60.0)$ & $22(59.5)$ & 0.971 \\
\hline No & $6(40.0)$ & $15(40.5)$ & \\
\hline
\end{tabular}

TME: Total mesorectal excision, LLND: lateral pelvic lymph node dissection, yp: postneoadjuvant pathological, CEA: carcinoembryonic antigen, LLN: lateral pelvic lymph node, NA: not applicable. *Tumors were classified according to the American Joint Committee on Cancer TNM system (13).

The 5-year recurrence-free survival (RFS) rate was significantly better in patients with LLNs of $<7.0 \mathrm{~mm}(\mathrm{n}=13)$ than in those with LLNs of $\geq 7.0 \mathrm{~mm}(\mathrm{n}=39)(85.7 \%$ versus $56.8 \% ; p=0.038$ ) (Figure 3 ). The 5-year OS rate also tended to be better in patients with LLNs $<7.0 \mathrm{~mm}$ than in those with LLNs $\geq 7.0 \mathrm{~mm}$ (100\% versus $84.1 \%$; $p=0.098)$.

\section{Discussion}

Recently, the Japan Clinical Oncology Group (JCOG) reported the results of a multicenter, randomized, controlled trial (JCOG0212) that aimed to confirm the non-inferiority of TME compared with TME with LLND for cStage II/III low rectal
Table II. Operative and oncological outcomes.

\begin{tabular}{|c|c|c|c|}
\hline & $\begin{array}{l}\text { TME } \\
(\mathrm{n}=15)\end{array}$ & $\begin{array}{c}\text { TME+LLND } \\
(\mathrm{n}=37)\end{array}$ & $p$-Value \\
\hline \multicolumn{4}{|l|}{ Operative procedure, $\mathrm{n}(\%)$} \\
\hline Low anterior resection & $6(40.0)$ & $6(16.2)$ & 0.065 \\
\hline Miles/Hartmann & $9(60.0)$ & $31(83.8)$ & \\
\hline \multicolumn{4}{|l|}{ Surgical approach, n (\%) } \\
\hline Laparoscopy & $9(60.0)$ & $19(51.4)$ & 0.571 \\
\hline Open & $6(40.0)$ & $18(48.6)$ & \\
\hline \multicolumn{4}{|l|}{ Operative time, $\min$} \\
\hline Median (range) & $\begin{array}{c}436 \\
(256-583)\end{array}$ & $\begin{array}{c}562 \\
(300-1135)\end{array}$ & 0.015 \\
\hline \multicolumn{4}{|l|}{ Estimated blood loss, $\mathrm{g}$} \\
\hline Median (range) & $\begin{array}{c}135 \\
(0-5345)\end{array}$ & $\begin{array}{c}560 \\
(0-4200)\end{array}$ & 0.053 \\
\hline \multicolumn{4}{|l|}{ Blood transfusion, n (\%) } \\
\hline Yes & $5(33.3)$ & $15(40.5)$ & 0.628 \\
\hline No & $10(66.7)$ & $22(59.5)$ & \\
\hline \multicolumn{4}{|c|}{ Postoperative complication, $\mathrm{n}(\%)^{\mathrm{a}}$} \\
\hline Total & $6(42.9)$ & $14(37.8)$ & 0.743 \\
\hline Perineal wound infection & 3 & 5 & \\
\hline Perineal wound dehiscence & 0 & 3 & \\
\hline Lymphorrhea & 0 & 2 & \\
\hline Ileus & 2 & 3 & \\
\hline Deep vein thrombosis & 1 & 2 & \\
\hline Anastomotic leakage & 1 & 1 & \\
\hline Other & 3 & 6 & \\
\hline \multicolumn{4}{|l|}{ Recurrence, n (\%) } \\
\hline Local & $0(0)$ & $9(17.3)$ & 0.066 \\
\hline Distant & $2(13.3)$ & $10(27.0)$ & 0.479 \\
\hline Lung/Liver & $1(2.7)$ & $7(18.9)$ & \\
\hline Bone & $0(0)$ & $1(2.7)$ & \\
\hline Inguinal & $1(2.7)$ & $0(0)$ & \\
\hline Dissemination & $0(0)$ & $1(2.7)$ & \\
\hline Lung lymph node & $0(0)$ & $1(2.7)$ & \\
\hline
\end{tabular}

TME: Total mesorectal excision, LLND: lateral pelvic lymph node

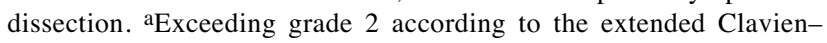
Dindo classification (14).

cancer (15). In JCOG0212, the OS and RFS rates for the TME with LLND group were significantly better than for the TMEonly group. Accordingly, TME with LLND remains a standard treatment for locally advanced low rectal cancer in Japan. However, there have been only a limited number of studies investigating the size of LLNs as a means of predicting pathological metastasis. Ishibe et al. reported a cut-off value of $10 \mathrm{~mm}$ (AUC=0.79, sensitivity $=43.8 \%$, and specificity $=98.5 \%$ ) to be useful in avoiding unnecessary LLND (16). Akiyoshi et al. reported the optimal cut-off value as a short-axis diameter of $8.0 \mathrm{~mm}$ before CRT (AUC $=0.86$, sensitivity $=68 \%$, and specificity $=85 \%$ ) (17). Our criterion of $\geq 7.0 \mathrm{~mm}$ before CRT seems stricter but more adequate than these previously described criteria, because our study showed a better AUC value, sensitivity, and specificity ( $\mathrm{AUC}=0.92$, sensitivity= $85.7 \%$, and specificity $=84.0 \%$ ). In addition, the five-year RFS 


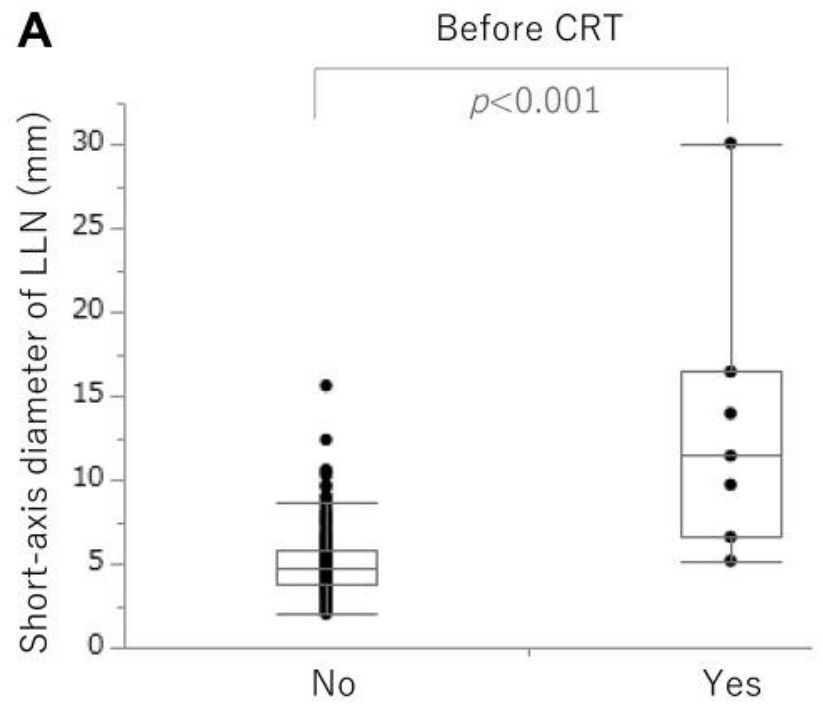

LLN metastasis
B

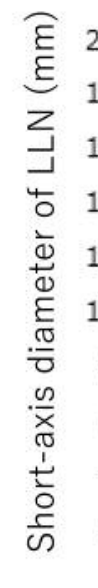

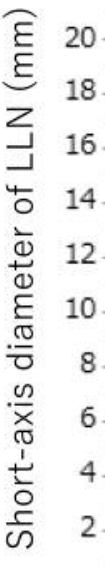

No

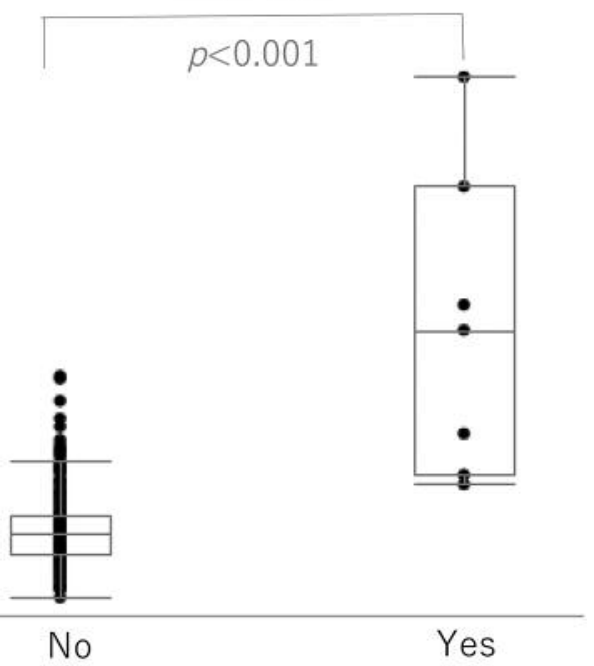

After CRT

LLN metastasis

Figure 1. Relation between the short-axis diameter and pathological metastasis of lateral lymph nodes. The short-axis diameter of lateral pelvic lymph nodes (LLNs) with pathological metastasis was significantly larger than that without pathological metastasis, both before (A) and after (B) preoperative chemoradiotherapy (CRT).

was significantly better in patients with LLNs $<7.0 \mathrm{~mm}$ than in those with LLNs $\geq 7.0 \mathrm{~mm}(85.7 \%$ versus $56.8 \%$; $p=0.038)$ in our study. Akiyoshi et al. found no significant correlation between the RFS and their cut-off value of $8.0 \mathrm{~mm}$ before CRT $(p=0.2291)$. The 5-year OS in our study also tended to be better in patients with LLNs $<7.0 \mathrm{~mm}$ than in those with LLNs $\geq 7.0 \mathrm{~mm}$ before CRT $(p=0.098)$. Therefore, our new criterion of a cut-off value of $7.0 \mathrm{~mm}$ before CRT may predict pathological metastasis of LLNs more effectively and accurately than the previously recommended values.

Several investigators have proposed cut-off values using MRI $(15,16)$. The usefulness of functional MRI for predicting quantitative treatment responses in rectal cancer has also been reported (18). In our study, we mainly used CT as the evaluation tool for LLN metastasis because it allows the evaluation of lymph node size with finer slices than MRI. The sensitivity of $85.7 \%$ and specificity of $84.0 \%$ of CT in diagnosing LLN metastasis in our study were not inferior to those of previous reports using MRI. PET examination was also used in predicting the metastatic LLN status in our study. Two patients with LLNs $<7.0 \mathrm{~mm}$ underwent LLND because of positive accumulation in PET, but neither were found to have pathologically-positive metastases. Although CT seems to be the most powerful tool for detecting pathologically positive LLNs, we still recommend a comprehensive assessment using CT, MRI, and PET.

It remains difficult to predict micrometastasis in LLNs by size alone. Yamaoka et al. reported that $2.3 \%$ of patients with
LLNs $\leq 3.0 \mathrm{~mm}$ in short-axis diameter had pathological metastases even when they did not receive preoperative CRT (19). Brown et al. (20) and Park et al. (21) reported that LLNs $<3.0 \mathrm{~mm}$ could not be detected on MRI. In the present study, there was no local recurrence in the group treated with TME alone, suggesting that possible micrometastases in LLNs $<7.0 \mathrm{~mm}$ might be controlled by CRT alone.

Several investigators have reported that LLNs shrink in size after CRT. Yamaoka et al. reported that the cut-off value of LLN size for the determination of metastasis decreased after CRT (19), which our results is consistent with. In fact, most LLNs shrank after CRT in the present study. Only one case showed an increase in the LLN size after CRT (5.2 mm before and $12.4 \mathrm{~mm}$ after CRT), and this LLN was pathologically positive for metastasis. Oh et al. reported that patients with an unchanged size of LLNs after CRT had a significantly higher incidence of LLN metastasis than those whose LLNs were responsive to CRT in terms of decreasing in size $(61 \%$ vs. $0 \% ; p<0.0001)$ (22). Therefore, we recommend performing LLND in cases with increased LLN size after CRT, even if the short-axis diameter of LLNs before CRT was shorter than $7.0 \mathrm{~mm}$.

This study had several important limitations. Firstly, it was a single-center retrospective study. Secondly, our study population diagnosed with pathologically LLN metastasis was very small. However, we believe that preoperative CRT dramatically reduced the number of metastatic LLNs after surgery because of the treatment effect. Further 
A

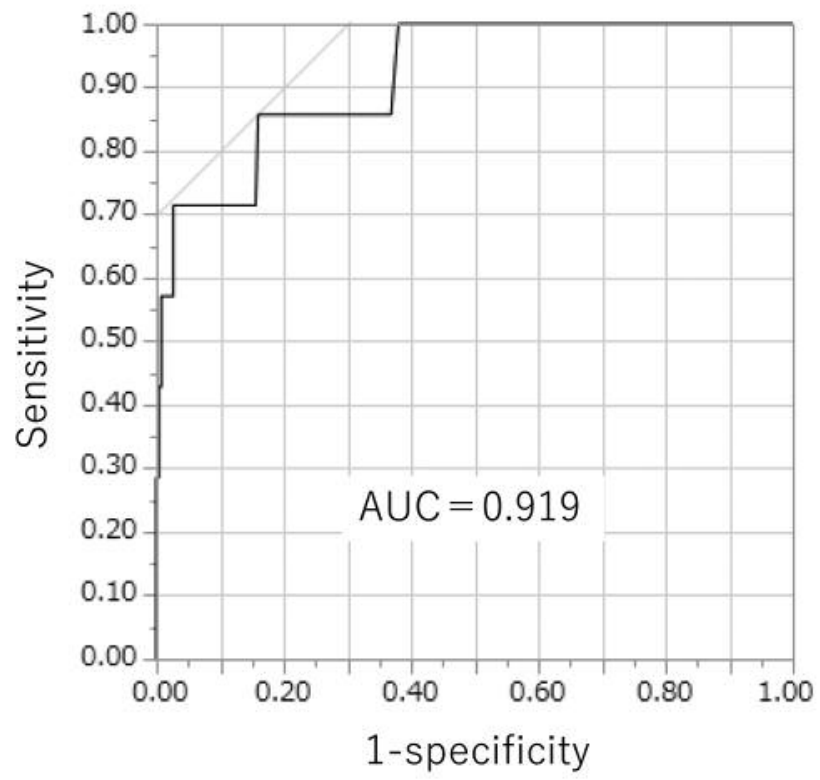

Cut-off value $=7.0 \mathrm{~mm}$
B $\quad$ After CRT

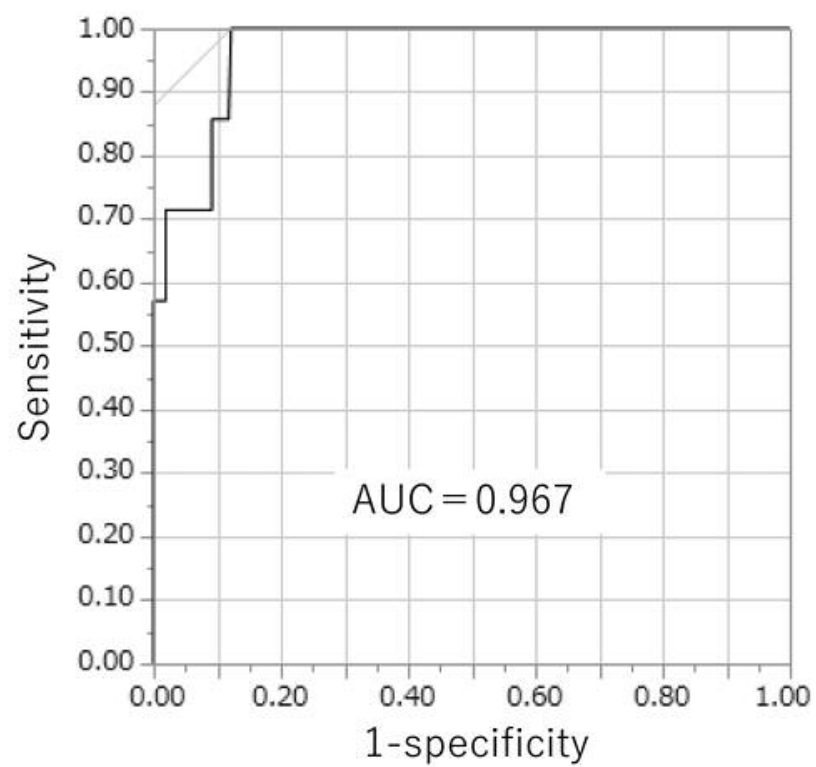

Cut-off value $=6.0 \mathrm{~mm}$

Figure 2. Receiver operating characteristic (ROC) curve analysis. The cut-off value of the short-axis diameter of lateral pelvic lymph nodes (LLNs) before (A) and after (B) preoperative chemoradiotherapy $(C R T)$ was 7.0 and $6.0 \mathrm{~mm}$, respectively. AUC: Area under the ROC curve.

A

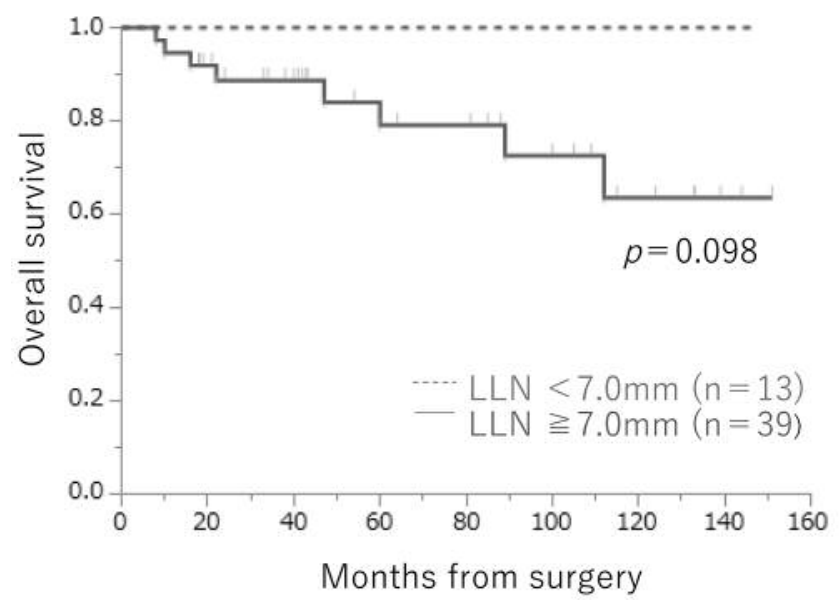

B

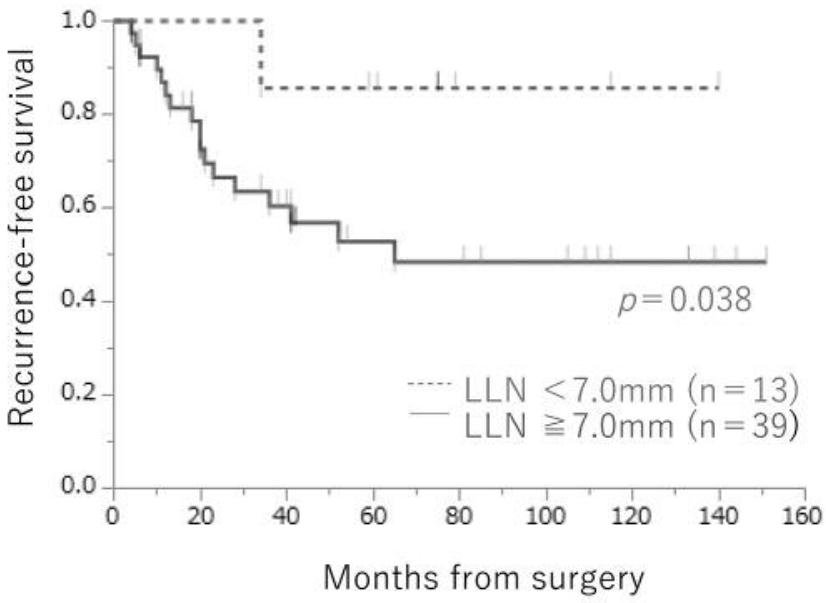

Figure 3. Kaplan-Meier curves for overall (OS) (A) and recurrence-free (RFS) (B) survival in patients with rectal cancer according to the size of lateral pelvic lymph nodes (LLNs). The 5-year OS rate was $100 \%$ and $84.1 \%$ for patients with LLNs $<7.0 \mathrm{~mm}$ and LLNs $\geq 7.0 \mathrm{~mm}$, respectively ( $p=0.098)$. The corresponding 5-year RFS rates were $85.7 \%$ and $56.8 \%$, respectively $(p=0.038)$.

studies employing more patients who undergo LLND without preoperative CRT are needed to confirm our results.

In conclusion, the optimal cut-off value for predicting pathological metastasis of LLNs in patients with low rectal cancer in our study was $7.0 \mathrm{~mm}$ before and $6.0 \mathrm{~mm}$ after CRT, respectively. The size of LLNs also seemed to predict the oncological outcome. The size criterion might be useful to select patients who are likely to benefit from LLND following preoperative CRT in multimodal therapy. 


\section{Conflicts of Interest}

The Authors declare that they have no conflicts of interest in regard to this study.

\section{References}

1 Georgiou P, Tan E, Gouvas N, Antoniou A, Brown G, Nicholls RJ and Tekkis $\mathrm{P}$ : Extended lymphadenectomy versus conventional surgery for rectal cancer: a meta-analysis. Lancet Oncol 10: 1053-1062, 2009.

2 Kusters M, Beets GL, van de Velde CJ, Beets-Tan RG, Marijnen CA, Rutten HJ, Putter H and Moriya Y: A comparison between the treatment of low rectal cancer in Japan and the Netherlands, focusing on the patterns of local recurrence. Ann Surg 249: 229235, 2009.

3 Tanaka S and Mori T: Letter: Radiological findings do not support lateral residual tumour as a major cause of local recurrence of rectal cancer (Br J Surg 2006; 93: 113-119). Br J Surg 93: 506-507; author reply 507, 2006.

4 Watanabe T, Itabashi M, Shimada Y, Tanaka S, Ito Y, Ajioka Y, Hamaguchi T, Hyodo I, Igarashi M, Ishida H, Ishiguro M, Kanemitsu Y, Kokudo N, Muro K, Ochiai A, Oguchi M, Ohkura Y, Saito Y, Sakai Y, Ueno H, Yoshino T, Fujimori T, Koinuma N, Morita T, Nishimura G, Sakata Y, Takahashi K, Takiuchi H, Tsuruta O, Yamaguchi T, Yoshida M, Yamaguchi N, Kotake K and Sugihara K: Japanese Society for Cancer of the Colon and Rectum (JSCCR) guidelines 2010 for the treatment of colorectal cancer. Int J Clin Oncol 17: 1-29, 2012.

5 Akiyoshi T, Watanabe T, Miyata S, Kotake K, Muto T and Sugihara K: Results of a Japanese nationwide multi-institutional study on lateral pelvic lymph node metastasis in low rectal cancer: is it regional or distant disease? Ann Surg 255: 1129-1134, 2012.

6 Kobayashi H, Mochizuki H, Kato T, Mori T, Kameoka S, Shirouzu K and Sugihara K: Outcomes of surgery alone for lower rectal cancer with and without pelvic sidewall dissection. Dis Colon Rectum 52: 567-576, 2009.

7 Ueno M, Oya M, Azekura K, Yamaguchi T and Muto T: Incidence and prognostic significance of lateral lymph node metastasis in patients with advanced low rectal cancer. Br J Surg 92: 756-763, 2005.

8 Ueno H, Mochizuki H, Hashiguchi Y, Ishiguro M, Miyoshi M, Kajiwara Y, Sato T, Shimazaki H and Hase K: Potential prognostic benefit of lateral pelvic node dissection for rectal cancer located below the peritoneal reflection. Ann Surg 245: 80-87, 2007.

9 Fujita S, Akasu T, Mizusawa J, Saito N, Kinugasa Y, Kanemitsu Y, Ohue M, Fujii S, Shiozawa M, Yamaguchi T and Moriya Y: Postoperative morbidity and mortality after mesorectal excision with and without lateral lymph node dissection for clinical stage II or stage III lower rectal cancer (JCOG0212): Results from a multicentre, randomised controlled, non-inferiority trial. Lancet Oncol 13: 616-621, 2012.

10 Morikawa E, Yasutomi M, Shindou K, Matsuda T, Mori N, Hida J, Kubo R, Kitaoka M, Nakamura M, Fujimoto K, Inufusa H, Hatta $\mathrm{M}$ and Izumoto G: Distribution of metastatic lymph nodes in colorectal cancer by the modified clearing method. Dis Colon Rectum 37: 219-223, 1994.

11 Nagawa H, Muto T, Sunouchi K, Higuchi Y, Tsurita G, Watanabe $\mathrm{T}$ and Sawada $\mathrm{T}$ : Randomized, controlled trial of lateral node dissection vs. nerve-preserving resection in patients with rectal cancer after preoperative radiotherapy. Dis Colon Rectum 44: 1274-1280, 2001.

12 Matsuda T, Sumi Y, Yamashita K, Hasegawa H, Yamamoto M, Matsuda Y, Kanaji S, Ohikiri T, Nakamura T, Suzuki S and Kakeji Y: Outcomes and prognostic factors of selective lateral pelvic lymph node dissection with preoperative chemo-radiotherapy for locally advanced rectal cancer. Int J Colorectal Dis 33: 367-374, 2018.

13 Edge SB and Compton CC: The American Joint Committee on Cancer: the 7th edition of the AJCC cancer staging manual and the future of TNM. Ann Surg Oncol 17: 1471-1474, 2010.

14 Katayama H, Kurokawa Y, Nakamura K, Ito H, Kanemitsu Y, Masuda N, Tsubosa Y, Satoh T, Yokomizo A, Fukuda H and Sasako M: Extended Clavien-Dindo classification of surgical complications: Japan Clinical Oncology Group postoperative complications criteria. Surg Today 46: 668-685, 2016.

15 Fujita S, Mizusawa J, Kanemitsu Y, Ito M, Kinugasa Y, Komori K, Ohue M, Ota M, Akazai Y, Shiozawa M, Yamaguchi T, Bandou H, Katsumata K, Murata K, Akagi Y, Takiguchi N, Saida Y, Nakamura K, Fukuda H, Akasu T and Moriya Y: Mesorectal excision with or without lateral lymph node dissection for clinical stage II/III lower rectal cancer (JCOG0212): A multicenter, randomized controlled, noninferiority trial. Ann Surg 266: 201-207, 2017.

16 Ishibe A, Ota M, Watanabe J, Suwa Y, Suzuki S, Kanazawa A, Watanabe K, Ichikawa Y, Kunisaki C and Endo I: Prediction of lateral pelvic lymph-node metastasis in low rectal cancer by magnetic resonance imaging. World J Surg 40: 995-1001, 2016.

17 Akiyoshi T, Matsueda K, Hiratsuka M, Unno T, Nagata J, Nagasaki T, Konishi T, Fujimoto Y, Nagayama S, Fukunaga Y and Ueno M: Indications for lateral pelvic lymph node dissection based on magnetic resonance imaging before and after preoperative chemoradiotherapy in patients with advanced lowrectal cancer. Ann Surg Oncol 22(Suppl 3): S614-620, 2015.

18 Pham TT, Liney GP, Wong K and Barton MB: Functional MRI for quantitative treatment response prediction in locally advanced rectal cancer. Br J Radiol 90: 20151078, 2017.

19 Yamaoka Y, Kinugasa Y, Shiomi A, Yamaguchi T, Kagawa H, Yamakawa Y, Numata $M$ and Furutani A: Preoperative chemoradiotherapy changes the size criterion for predicting lateral lymph node metastasis in lower rectal cancer. Int $\mathbf{J}$ Colorectal Dis 32: 1631-1637, 2017.

20 Brown G, Richards CJ, Bourne MW, Newcombe RG, Radcliffe AG, Dallimore NS and Williams GT: Morphologic predictors of lymph node status in rectal cancer with use of high-spatialresolution MR imaging with histopathologic comparison. Radiology 227: 371-377, 2003.

21 Park JS, Jang YJ, Choi GS, Park SY, Kim HJ, Kang H and Cho $\mathrm{SH}$ : Accuracy of preoperative MRI in predicting pathology stage in rectal cancers: node-for-node matched histopathology validation of MRI features. Dis Colon Rectum 57: 32-38, 2014.

22 Oh HK, Kang SB, Lee SM, Lee SY, Ihn MH, Kim DW, Park JH, Kim YH, Lee KH, Kim JS, Kim JW, Kim JH, Chang TY, Park SC, Sohn DK, Oh JH, Park JW, Ryoo SB, Jeong SY and Park KJ: Neoadjuvant chemoradiotherapy affects the indications for lateral pelvic node dissection in mid/low rectal cancer with clinically suspected lateral node involvement: A multicenter retrospective cohort study. Ann Surg Oncol 21: 2280-2287, 2014.

Received December 15, 2018

Revised December 25, 2018

Accepted January 7, 2019 